\title{
Applied information system-based in enhancing students' understanding towards higher order thinking (HOTS)
}

\begin{abstract}
The application of information and communications technology (ICT) had become more important in our daily life, especially in educational field. Teachers are encouraged to use information system-based in teaching Mathematical courses. Higher Order Thinking Skills (HOTS) approach is unable to explain using chalk and talk methods. It needs students to analyze, evaluate, and create by their own natural abilities. The aim of this research study was to evaluate the effectiveness of the application information system-based in enhance the students understanding about HOTS question. Mixed-methods or quantitative and qualitative approach was applied in collecting data, which involve only the standard five students and the teachers in Sabak Bernam, Selangor. Pra-postests was held before and after using information system-based in teaching to evaluate the studentsôunderstanding. The result from post-test indicates significant improvement which proves that the use of information system based able to enhance studentsôunderstanding about HOTS question and solve it. There were several factor influenced the students such as studentsôattitude, teachers attraction, school facilities, and computer approach. Teachers play an important role in attracting students to learn. Therefore, the school should provide a conducive learning environment and good facilities for students to learn so that they are able to access more information and always exposed to new knowledge. As conclusion, information system-based are able to enhance students understanding the need of HOTS questions and solve it.
\end{abstract}

Keyword: HOTS; Information system-based; Mathematics education; Mixed methods 